\title{
Visitando las estrellas: Martín Gil y el discurso de divulgación astronómica en la Argentina de comienzos del siglo $\mathrm{XX}$
}

Paulina Maritza Brunetti

Escuela de Ciencias de la Información de la Universidad Nacional de Córdoba

\section{Resumen}

Recibido: 15 de octubre de 2012

Aceptado: 31 de octubre de 2012

La historia de la divulgación científica en la Argentina es rica en formatos, escrituras y autores, muchos de los cuales permanecen aun hoy desconocidos. Este trabajo tiene como objetivo la indagación de las condiciones de producción, circulación y recepción de los artículos de un divulgador de la astronomía cordobés publicados en el diario La Nación durante casi cuarenta años. Su labor se inició aproximadamente en 1906 o 1907 y fue continua y exitosa. A pesar de ello, ha sido olvidado quizás porque adhería a una teoría que la comunidad científica de su época desvalorizaba y que en la actualidad aun podría desecharla. Sin embargo, su labor estuvo determinada por factores que convergieron, de todas maneras, para erigirlo en la figura social del divulgador. Más allá de los rechazos académicos, el éxito de sus textos plantea interrogantes que se procuran responder a través del análisis de sus artículos. Importa considerar para ello no solo la temática abordada sino también un estilo que se muestra consciente del soporte en el que escribía. Sus textos muestran una dinámica discursiva centrada en la explicación de fenómenos vinculados con la astronomía, pero nunca ajena a la selección de una estrategia discursiva global que convocaba a la lectura atrayente y placentera. Palabras clave: divulgación astronómica; análisis de diarios; lectura; retórica.

\section{Visiting the stars: Martin Gil and the discourse of astronomic publishing in Argentina at the beginning of the $20^{\text {th }}$ Century}

\section{Abstract}

The history of the popularization of science in Argentina is rich in formats, texts, and authors, many of whom remain unknown even today. The aim of this paper is to examine the conditions of production, circulation, and reception surrounding the articles written by a cordovan astronomer for La Nación newspaper during almost forty years. His work began approximately in 1906 or 1907, and it was both continuous and successful. Despite this fact, he has been forgotten, perhaps because he adhered to a theory disparaged by 
his contemporary scientific community, and which could still be discredited in modern times. Nevertheless, his work was determined by factors that converged to shape him into the social figure of a popular scientist. Despite academic rejection, the success of his texts poses questions that this essay hopes to answer through the analysis of his articles. For this purpose, it is important to consider, not only the themes he dealt with, but also his style, which was mindful of the medium he was writing for. His texts show a discursive dynamic centered on the explanation of phenomena related to astronomy, but which never ignores a global discursive strategy that calls for pleasing and attractive reading.

Keywords: astronomic publishing; newspapers analysis; reading; rhetoric.

\section{Visitando as estrelas: Martín Gil e o discurso de divulgação astronômica na Argentina do começo do século XX}

\section{Resumo}

A história da divulgação científica na Argentina é abundante em formatos, escrituras e autores, muitos dos quais permanecem ainda hoje desconhecidos. Este trabalho tem como objetivo a pesquisa das condições de produção, circulação e recepção dos artigos de um "divulgador cordobés" da astronomia, publicados no jornal La Nación durante quase quarenta anos. Seu trabalho começou aproximadamente no ano 1906 ou 1907 e foi contínuo e exitoso. Apesar disso, foi esquecido; talvez porque aderia a uma teoria que a comunidade científica da sua época desvalorizava e que ainda hoje poderia rejeitá-la. Porém, seu trabalho esteve determinado por fatores que confluíram no posicionamento da figura social do divulgador. Além de ser rejeitado academicamente, o sucesso dos seus textos apresenta questões que costumam ser respondidas através da análise dos seus artigos. Nesse caso, leva-se em consideração não apenas a temática abordada, mas também um estilo que se manifesta consciente do suporte em que escrevia. Seus textos se apresentam em uma dinâmica discursiva centrada na explicação de fenômenos vinculados à astronomia, mas jamais alheia à seleção de uma estratégia discursiva global que convocava à leitura atraente e prazerosa.

Palavras-chave: divulgação astronômica; análise de jornais; leitura; retórica.

\section{Introducción}

La divulgación científica ha sido considerada solo recientemente desde una perspectiva histórica en la Argentina ${ }^{1}$. El interés en estos últimos años por la vulgarización de la ciencia en general y de la astronomía en particular a través de los medios de comunicación y la jerarquía que ha adquirido no puede ocultar una larga historia que tuvo sus comienzos en antiguas hojas periodísticas, y luego se fue desarrollando con mayor intensidad especialmente en los primeros años del siglo $\mathrm{XX}$. Los interrogantes son todavía numerosos y restan análisis que profundicen

\footnotetext{
1 Existen referencias en diversos libros destinados a la historia de la prensa argentina. Particularmente véase, por ejemplo, Sarlo (1992) y para un panorama abarcador, Cazaux (2010).
} 
en concepciones de divulgación según sus temporalidades, en los discursos de sus autores y en la emergencia de figuras sociales vinculadas con el campo, en tanto si la prensa siempre se ocupó del tema, en oportunidades fue como parte de sus rutinas informativas.

Nuestro objetivo es contextualizar y analizar los discursos de un divulgador de la astronomía célebre en su tiempo en la Argentina y a quien no se ha reconocido suficientemente como tal. Su nombre era Martín Gil. Nació en 1868 en Córdoba; estudió abogacía aunque no terminó su carrera. Había heredado tierras de su padre por lo que pasó mucho tiempo en el espacio rural. Residió en la ciudad de Córdoba y luego en Buenos Aires. Fue un aficionado a la astronomía y hombre de letras, ocupó el cargo de ministro de Obras Públicas durante la gobernación de Ramón J. Cárcano (1913-1916) y después, en la línea del Partido Demócrata, fue senador provincial y diputado nacional desde 1926 a 1930. Publicó numerosos libros ${ }^{2}$, la mayoría de los cuales fueron recopilaciones de sus artículos publicados durante cuarenta años en el diario La Nación, donde posiblemente inició sus columnas periodísticas entre 1901 o 1902 y a partir de 1906 o 1907, dedicadas específicamente a la divulgación astronómica. Sus escritos en la prensa no eran semanales y en oportunidades podía transcurrir más de mes y medio entre ellos o a veces aparecían dos en el mismo mes ${ }^{3}$. No obstante, fue un colaborador regular y con el paso del tiempo sus textos fueron ocupando un espacio central en las páginas del diario.

Muy conocido en su momento y estimado por el público lector, ha sido olvidado o en todo caso se lo menciona fugazmente, en oportunidades con cierto tono peyorativo, dando cuenta de una tensión motivada por causas disímiles entre el campo de la ciencia y su difusión, pero posible de interrogar en su propia temporalidad.

Aun cuando no podemos detenernos demasiado en ello, resulta necesario contextualizar los artículos de Martín Gil en cuanto emergen condiciones de producción que se vinculan especialmente con la identidad que supo construir como comunicador, lo que permite repensar el discurso de la divulgación científica

\footnotetext{
2 Entre otros: Modos de ver, Agua mansa, Cosas de arriba, Prosa rural, Celestes y cósmicas, Mirar desde arriba, Un anillo desaparecido, Hablando solo, Misterios, planetas y petróleos. No todos son de divulgación científica. Sus libros tuvieron numerosas ediciones. En la bibliografía solo se consigna la edición consultada en la que no siempre figura la fecha de la primera edición.

3 Secciones y columnas tampoco tenían en la época la estabilidad y regularidad que conocemos hoy.
} 
arrojando luz también sobre las tensiones y conflictos que surgieron en las primeras décadas del siglo XX.

\section{La divulgación científica a comienzos del siglo XX en la Argentina}

¿Qué concepto de la divulgación científica se tenía en la primera década del siglo XX? ¿Qué disponibilidad mostraban los científicos para la divulgación? En 1908, el Museo de la Universidad Nacional de La Plata comenzó la publicación de la Biblioteca de difusión científica, cuyo segundo tomo lo redactó el doctor en química Enrique Herrero Ducloux. Francisco Lavalle, quien era doctor en farmacia, le envió una carta de felicitación ${ }^{4}$ a través de la cual es posible inferir la idea de "vulgarización" o "divulgación” de quienes apostaban por ella. Lavalle expresó algunos conceptos reveladores. En primer lugar, señaló la resistencia de muchos miembros de la comunidad científica a divulgar sus conocimientos: "Opino que la ciencia en sus diferentes ramas está infinitamente menos difundida de lo que debiera estar, porque los que la cultivan no se despojan de su carácter sacerdotal [...] Muchos creen impropio de la seriedad doctoral descender al terreno de la vulgarización".

En segundo lugar insistía en que era necesario "el conocimiento de las leyes que rigen la materia, el de los fenómenos físicos y químicos, el de los hechos naturalísimos" en tanto "por su carácter hieren la imaginación del vulgo indocto, que no pudiendo explicárselos, los atribuye a la acción de seres sobrenaturales, ó a la voluntad divina, perdurando de esa manera en él el espíritu supersticioso que le aterra..." Se concebía así la divulgación como una tarea necesaria de dilucidación y esclarecimiento para quienes, al ignorar las investigaciones científicas, albergaban antiguas convicciones. En esta concepción de una "ciencia pedagógica" subyacía la idea del público como "pueblo-niño" de sombrías y erradas creencias. Cuando Martín Gil falleció, el diario La Nación señalaba, entre otras cosas, que había contratado sus servicios a comienzos del siglo XX "para que una parte del público no creyese más en díceres y el resto del público tuviese al alcance de la mano la sensación y explicación de misterios" ". La idea no era extraña para una época que advertía nuevas e importantes mutaciones en el camino de la ciencia y sus funciones, pero sí resulta significativa la preocupación -al menos en un número reducido de científicos y en la prensa en general- por una difusión que procuraba aproximar a los lectores conocimientos que habrían de alterar numerosas sugestiones,

\footnotetext{
La Nación, 4 de mayo de 1908.

La Nación, 10 de diciembre de 1955.
} 
temores y fascinaciones. La tercera idea de Lavalle se refería a cómo realizar la tarea, espacio discursivo en el que vinculaba el discurso científico y el literario: la escritura literaria de la ciencia era considerada como un signo necesario del trabajo de vulgarización, partiendo del presupuesto de que el discurso científico era irreductiblemente impenetrable y cerrado. Así le decía Lavalle a Herrero Ducloux:

Es usted un estudioso y un observador, así como es también un hombre de ciencia y un literato. Sus trabajos lo proclaman y lo manifiestan. Lo que el hombre de ciencia ha visto y desentrañado, lo expone el hombre de letras en períodos brillantes [...] de un estilo florido y sencillo á la vez a todos comprensible, y que penetra llevando el concepto hasta los más recónditos rincones del cerebro [...]. Esa duplicidad de forma, esa doble individualidad que debe acompañar al que en la cátedra ó el libro aborda las especulaciones didácticas [...] enseñar deleitando, es la que le distingue á usted y le inscribe en esa falange de jóvenes heraldos de la ciencia argentina, que trabajan incansablemente por el esplendor y difusión de los conocimientos que otrora fueron patrimonio de uno pocos [...] sus producciones se leen con placer, porque en ellas halla alimento sabroso la afición científica y el gusto estético ${ }^{6}$.

Cuando Lavalle trazó la alianza entre ciencia y literatura como una fórmula feliz y exitosa, ¿qué estaba pensando al decir "literatura" o cuando creía que para divulgar es necesario el atributo de ser "literato"? Por las pocas palabras que añadió parece utilizar todas estas expresiones como un polo opuesto a la fría y severa escritura científica, sin que ello signifique la determinación de un género en particular aunque agregó en la misma nota que muchos conocimientos habían llegado al público en general "en los repliegues de la novela, del cuento o del artículo festivo".

La búsqueda de una lengua agradable no reposa en el recurso a ornamentos, sino en el uso de una serie de estrategias discursivas que se ven como propias de la literatura y que, en más de un texto, nutren la prosa de algunas áreas del conocimiento y aun las del mismo periodismo. En este punto enraíza el éxito que envolvió a Martín Gil y que justifica el análisis de sus textos procurando observar aquellos "modos de hacer" que congregaron a un público interesado por la astronomía desde su cotidiana experiencia. No obstante, resulta necesario previamente señalar otras determinaciones del discurso de Martín Gil en cuanto algunas circunstancias de la Córdoba de comienzos de siglo que contribuyeron también a que viniera a cumplir una función a la que otros se resistían.

6 Se respeta en todas las citas la ortografía de los textos originales. 


\section{El contexto cordobés}

Los textos de Martín Gil sobre fenómenos celestes surgen en el marco de un clima adverso y tenso en cuanto a las relaciones entre la comunidad científica astronómica y la sociedad cordobesa. En 1871 se fundó en la ciudad de Córdoba el Observatorio Nacional Argentino (ONA) que dependía directamente del Ministerio de Instrucción Pública de la Nación. Sus primeros tres directores Benjamín Gould, John Thome y Charles Perrine- no contaron con la simpatía de la sociedad cordobesa por motivos diversos.

Los historiadores de la ciencia argentina mencionan divergencias entre el observatorio de Córdoba y el de La Plata en cuanto a las líneas investigativas en las que ambos se inscribían; mientras el primero lo hacía en la germana, el segundo se adscribía a la francesa. Esto habría influido de manera determinante en el desarrollo de las actividades de ambos observatorios y especialmente en el impulso de acciones conexas a la astronomía, como la docencia y la formación de recursos humanos argentinos en ese campo.

Un hecho significativo fue el aislamiento en el que se mantuvo el observatorio cordobés respecto de la comunidad. Se reconoce que no llegó "a interpretar acertadamente las demandas de la sociedad cordobesa, para darles satisfacción y consecuentemente poder integrarse plenamente a ella" (Paolantonio y Minniti, 2009: 104). Tanto Gould como Thome consideraban que no era función de una institución científica como el ONA ocuparse de cuestiones menores que podían interesar al público mayoritariamente inculto en astronomía. Paolantonio y Minniti dan como ejemplo de esa falta de comunicación un episodio interesante: en marzo de 1897, los diarios de Córdoba se enteraron del descubrimiento de un cometa a través de Thome a mediados de febrero de ese año por una noticia divulgada por la prensa extranjera. A esto se sumaba la negativa a admitir funciones de docencia, en tanto, según Perrine, la tarea de enseñanza, por ejemplo, hubiera provocado una disipación del esfuerzo que imperiosamente demandaba la investigación (Ibídem: 131).

Las reacciones cordobesas fueron severas y se manifestaron cuando se propuso anexar el ONA a la Universidad de Córdoba. En esa ocasión, el diputado Jerónimo del Barco fue especialmente duro con el establecimiento al denunciar que tenía fuertes vínculos con el extranjero pero que era casi desconocido en la Argentina, a lo que añadió: "No presta absolutamente ningún servicio a la ciencia nacional 
y es un centro o colonia de connacionales del director del establecimiento"7. Le reclamaba su ausencia de docencia e incluso lo acusaba a haber expulsado del observatorio a los argentinos "que allí estaban empleados y ha traído de Norte América otros para reemplazarlos" argumentando que a la juventud estudiosa del país le estaba vedado estar allí. Es posible pensar este conflicto en un marco político, científico y cultural complejo como el que trazó Diego Hurtado, en el que quedó desarrollada con claridad la situación de dependencia de la ciencia argentina respecto de la de países centrales; en tanto, "a lo largo de décadas, tanto desde el campo académico como político, quienes se dedicaron a pensar y elaborar políticas de ciencia y tecnología lo hicieron hinoptizados por los casos de Alemania, Estados Unidos; Japón..." (2010: 12). No obstante, la forma en que se desarrolló tal proceso en la Córdoba de comienzos de siglo y los modos en que se articularon las visiones respecto de sus relaciones con el ONA, estuvieron atravesados por otras y múltiples causas de orden político-partidario y aun personales ${ }^{8}$. Pero, y más allá de profundizaciones que retomen el tema, los artículos de Martín Gil estaban cruzados por esta tensión a la que no se encontraban ajenos los miembros del observatorio, en tanto a través de la prensa las críticas fueron mutuas. Un aficionado a la astronomía cuya actuación político-partidaria fue intensa mostró a los ojos del público un conflicto que, según él, lo excedía. "Se me ladra sencillamente porque soy argentino; porque no dispongo de un apellido difícil que me haga pasar por extranjero y porque no tengo título o rótulo universitario. $\mathrm{O}$ me río del inconveniente del apellido y del rótulo; de ser argentino me enorgullezco discretamente" (1917: 24) y hablaba irónicamente de la mirada culta extranjera para con "nosotros, "los salvajes de América' a quienes se les ha asignado el papel de 'indios mansos"'.

No es extraño, entonces, que en el curso de 1918, la Federación Universitaria de Córdoba lo incluyera en la lista de docentes que proponía para ocupar cátedras y planteó el nombramiento de Gil en la de Geofísica y meteorología, creada expresamente para él en la Facultad de Ciencias Exactas de la Universidad de Córdoba. No obstante, Gil renunció a ella antes de hacerse cargo. En su renuncia argumentó su falta de mérito para asumirla por cuanto se consideraba un simple "amateur"

\footnotetext{
Los Principios, 16 de enero de 1917.

8 El diputado Jerónimo del Barco pertenecía al mismo partido político que Martín Gil y lo había apoyado en el Congreso en iniciativas relativas a la creación de un observatorio de heliofísica y física cósmica (Paolantonio \& Minitti, 2009: 104). En 1926, M. Gil presentó en la Cámara de Diputados de la Nación el proyecto de ley sobre creación de la Dirección de Meteorología e Hidrometría suscrito también por los diputados nacionales Ernesto Padilla y Julio A. Roca. No obstante, no sería posible vincular todas sus iniciativas y/o conflictos con relaciones partidarias.
} 
sin título universitario que lo habilitara para el cargo. Además anunciaba su decisión de ausentarse definitivamente de Córdoba. La Voz del Interior, diario que en aquel momento estaba estrechamente vinculado con los estudiantes reformistas, narró y comentó el hecho en varias columnas. En ellas celebró la propuesta y exaltó la figura de Martín Gil:

La nueva Universidad había enriquecido su acervo con la adquisición de este maestro que incorporaba a los estudios de la casa, el conocimiento de una ciencia no oficializada aún casi desconocida: nadie podía profesarla con más autoridad que quien la enriqueciera con sus observaciones y la divulgara por todo el continente para que todos la comprendan, con esa sencillez profunda y clara del talento que da los jugos de su madurez, o se prodiga en dones de la propia cosecha limpia de extraña vegetación?.

No parece ingenua la última frase de $L a$ Voz del Interior cuando señalaba "con esa sencillez profunda y clara del talento $[. .$.$] que se prodiga en dones de la propia$ cosecha limpia de extraña vegetación", metáfora final que condensa la tensión a la que Martín Gil aludiría recurrentemente pero a la que hay que pensar en un marco conflictivo más amplio ${ }^{10}$.

Más allá de que el componente político fue relevante, era escasa en la comunidad científica de la época la vocación por la divulgación, como ya se ha señalado, y parece reiterarse recurrentemente aun cuando se observa en la prensa interés por hacerlo. Esto se infiere de múltiples notas de difusión de la astronomía aunque muchas llegadas desde el extranjero que, bajo distintos títulos, aparecían como Actualidad científica, Crónica científica o semejantes. Es cierto que algunas de esas notas, aunque no numerosas, estuvieron firmadas por Charles Perrine. No obstante, se plantea no solo un conflicto que posiblemente exceda el campo de la ciencia a comienzos del siglo XX sino también una suerte de barrera entre una ciencia puramente académica producida y leída por científicos y la débil emergencia de una ciencia explicada al público.

\section{El discurso de divulgación de Martín Gil}

Martín Gil vino así a instalarse en ese espacio que en la perspectiva de Lavalle aparecía como un reclamo en la época, pero su labor se inscribía en una antigua tradición propia de la astronomía que ostenta algunas particularidades: se trata

\footnotetext{
9 La Voz del Interior, 22 de noviembre de 1918.

10 A esto habría que añadir que se había suprimido la cosmografía de los planes de enseñanza de la escuela secundaria, solo reducida a algunas bolillas de introducción en cursos de geografía.
} 
de un saber de orígenes remotos; a pesar de ser una disciplina científica siempre contó con "amateurs" (clubes, asociaciones); y desde antiguo hubo también divulgadores célebres a nivel de libros (Beacco, 2000). Martín Gil no lo hizo en principio de esta forma sino a través de la prensa desde donde el quehacer transitaba en un amplio campo de lectores y este parece haber sido un paso esencial para la circulación de conocimientos, aun cuando La Nación no podría considerarse un diario popular. Como aficionado a la astronomía creía profundamente en la teoría electromagnética del sol, lo que señala con claridad:

Soy de los que consideran al sol como el corazón de nuestro pequeño universo, de nuestro sistema planetario... En la medida de mis fuerzas, soy, pues, partidario de la grandiosa teoría electrodinámica, ó si se quiere electromagnética del sol. Esta teoría afirma que el sol puede ser considerado como un inmenso electroimán, ó un solenoide, actuando por inducción sobre el cortejo de planetas que lo circundan y siguen -la Tierra, uno de ellos - los que a su vez deben actuar también como cuerpos imantados (1909: 115)

e hizo del sol el eje de la explicación de una serie de fenómenos, especialmente los meteorológicos y sísmicos, lo que lo animó a realizar regularmente pronósticos en la prensa con lo que concitó vivo interés hasta el punto de que los diarios - ya fueran nacionales o regionales- parecían estar pendientes de su palabra al respecto. Así es posible encontrar telegramas como el siguiente:

\section{DE MARTÍN GIL}

ANUNCIO DE NUEVAS LLUVIAS

Don Martín Gil nos telegrafió anoche lo siguiente: Córdoba. 8. Siento mucho mani-

festar que del 9 al 20 debemos tener momentos de grandes lluvias y tempestades ${ }^{11}$.

La redacción del título ("De Martín Gil”) presupone el claro conocimiento del público respecto del autor del telegrama. En varias oportunidades planteó que hacía sus pronósticos en función de una región perturbada del sol (1917: 40), lo que fue ásperamente criticado por la comunidad científica. Él mismo relata que un diario metropolitano hizo una entrevista al director del observatorio de La Plata quien planteó que los fenómenos solares carecían de importancia insinuando la antigüedad e inutilidad de esta teoría (1909: 111). A esto se sumaban críticas también aparecidas en la prensa en las que se desacreditaban sus pronósticos. Quizás por todo ello su trabajo periodístico quedó estrechamente vinculado con una posición desestimada científicamente, lo que encubrió una labor de divulgación que excedió la teoría a la que adhería a la vez que también escribió sobre numerosas

${ }_{11} \quad$ La Nación, 9 de enero de 1912. 
cuestiones astronómicas no siempre vinculadas con el sol y su influencia. Una recorrida por sus textos revela que se ocupó de los planetas, de los cometas, de la luna, de las estrellas, de los bólidos, de los viajes al polo, de la hora, etc.

No es propósito de este trabajo discutir la importancia o no de la teoría electromagnética, la que posiblemente no ameritaba aprobación en su momento, sino tratar de comprender su éxito como divulgador, como comunicador, en tanto la sola posesión de conocimientos no parece habilitar las cualidades para comunicarlo. Es en este plano discursivo donde se aloja quizás la legitimidad que durante años lo mantuvo en la prensa.

Cuando Alberto Gerchunoff prologó su libro Hablando solo, publicado en 1935, ya Gil tenía una larga trayectoria como divulgador y, al referirse a su tarea, señalaba que por su condición de estudioso pudo "popularizar lo que hasta ahora, por lo menos en nuestro país, preocupaba a grupos limitados", expresión con la que destacaba la emergencia de la figura social del vulgarizador. De tal éxito también da las razones:

El público siente en lo que escribe Martín Gil una fuerza indefinible y que es el privilegio de ser simpático, que no es desde luego una cualidad baladí. Ser, como Martín Gil, un escritor simpático, y a esto aspiran, en suma, los escritores, es decir a la posibilidad de comunicación y de influencia [...] Hay en Martín Gil una cordialidad comunicativa que anima el dato, el detalle técnico, la dilucidación del teorema (Gerchunoff, 1935).

No es poca la cualidad que se le atribuye, pero si bien el juicio es aparentemente sencillo, es necesario notar que arraiga en un profundo propósito cualquier escritor y que consiste en establecer con el lector - como lo señala Gerchunoffun vínculo de "comunicación y de influencia". Un breve recorrido por los textos de Martín Gil nos permitirá esclarecer esta condición de la que posiblemente no pueda carecer ningún divulgador. Cuando comenzó con sus artículos y pronósticos en La Nación era un desconocido. Así lo señalaba Pedro Echagüe:

Nadie le conocía entre nosotros. Aquel nombre de fácil eufonía, aquel probable seudónimo, despertó de inmediato la curiosidad del público; curiosidad que convirtió luego en vivo interés el contenido de sus artículos maliciosos y penetrantes en la observación (1938: 114-115).

Si en aquel período inicial supo ampararse en el diario que le abrió las puertas, los largos años subsiguientes no pudieron sino sostenerse en una legitimidad que por sí mismo fue alcanzando aun en contra de múltiples escollos. También la prensa de la ciudad de Córdoba reconocía, casi en los mismos términos que 
Gerchunoff, su aptitud para la divulgación. Así lo señala un artículo del diario Los Principios denominado "Córdoba y la astronomía":

El señor Martín Gil ha hecho simpática y atrayente a una ciencia que los sabios con su desmedida afición al símbolo matemático han hecho intolerable aún para muchos que no permitirían ser colocados entre los del vulgo a secas ${ }^{12}$.

El contacto y la comunicación con el otro no son simples. Como señala Charaudeau (1995), una serie de ideas puede hacer creer que el contacto con el otro "es una cosa fácil", pero la comunicación no significa transmitir mensajes unívocos con palabras porque las palabras no son "transparentes", tampoco consiste en anunciar "una intención preconstruida" por cuanto el lenguaje no es un reflejo del pensamiento, comunicar tampoco reside en el "hablar bien" o "de manera brillante"; al contrario, el más bello discurso puede resultar incomprensible. De manera que responder por qué Martín Gil fue reconocido como un gran divulgador de la astronomía naturalmente conduce a indagar las estrategias discursivas que legitimaron su imagen y lo volvieron una suerte de modelo de la divulgación

¿Cómo pensaba la divulgación científica? Parece haber escogido una retórica que se aleja en mucho de una concepción en oportunidades planteada en la actualidad, según la cual la divulgación solo sería una traducción de un registro académico por sí mismo complejo a otro registro más simple al alcance del público. Esto es, una suerte de doble lenguaje. En algunos de sus textos, él mismo problematiza la cuestión:

Uno de los inconvenientes más serios en la divulgación científica y muy especialmente en lo que respecta a la astronomía, estriba sin duda, en la dificultad de expresarse sin hacer uso de la terminología de precisión y mucho menos de la demostración matemática (1917: 131).

Podríamos suponer sin exageración que, de diez lectores, ocho miran a las matemáticas con inocente e injusto horror (1917: 135).

Desgraciadamente, el mundo es matemático - ha dicho Emerson- y no hay casualidad alguna en su vasta y flotante curva (1909: 24).

Más allá del juicio de los científicos coetáneos, en su labor divulgativa no faltó el rigor matemático, la terminología especializada, los cálculos trigonométricos, referencias a hipótesis comprobadas o a comprobar, reseñas de investigaciones científicas, discrepancias entre investigadores. La elección no fue el abandono de la precisión o de la complejidad - según él mismo lo plantea en la última cita

12 Citado en: Paolantonio y Minitti (2009: 104). 
transcrita- sino más bien un estilo cuya originalidad destacaron muchos contemporáneos en cuanto sus trabajos de divulgación, sin perder consistencia, cambiaron la escritura austera por otra en la que imperaban otros principios: el placer y la proximidad con el lector.

Martín Gil construyó su imagen discursiva de manera explícita e implícita. Se reconoció como un "amateur" cuya labor se encontró siempre inscrita en una particular tensión, como ya se ha dicho, pero especialmente concibió sus textos como un espacio de reciprocidad con los lectores habitando en ese grupo de narradores o escritores en quienes es notorio su interés por establecer con ellos un contacto o incluso un diálogo. Siempre vueltos hacia su público, observa Genette (1989; 309), se los podría llamar más bien "causeurs" y quizás la función "a la que suelen dar preferencia" se la podría denominar "función de comunicación", esto es, la de un "contar a" necesariamente variable según las previsiones que la instancia de enunciación haya realizado de su lector.

Ya sea oral o escrita, la comunicación es siempre un fenómeno de intercambio que requiere del reconocimiento mutuo. Martín Gil concebía los textos de divulgación como una conversación, es decir, son textos dialógicos en su sentido más primordial, en los que la presencia del lector era asidua. En todos sus artículos reclamó recurrentemente su participación a través las fórmulas rituales de sociabilidad y cortesía: "Quizás el lector recuerde aquello de que...", "Si me lo permite en el lector..." "El lector o lectora amables pueden elegir la manera de ver más de conformidad con su criterio propio...", "Pero disculpe el lector o la interesante lectora, mi intención no ha sido divagar sobre el concepto de tiempo..." Las gramáticas antiguas llamaban a los vocativos "excitantes de la atención" y los consideraban una apoyatura del diálogo, particularmente un sostén manifiesto de afectividad conversacional que no solo llamaba la atención para que el oyente o lector se sintiese estimulado a atender, sino también para que se sintiera más reconocido. Más allá de estos vocativos, el tono conversacional combinaba armoniosamente la explicación en el marco de un diálogo en el que el discurso discurría a través de numerosos recursos cercanos a la oralidad como los comentarios intercalados, las reflexiones sobre la actualidad, los marcadores conversacionales ("bueno", "sigamos", etc.), las referencias históricas o literarias, las anécdotas. Dentro de este marco, nunca estuvieron ausentes los rasgos de humor referidos muchos de ellos a los aspectos socio-políticos de la Argentina del momento: 
Investiguemos como andan las relaciones de $\mathrm{Sirio}^{13} \mathrm{con}$ el Sol, en pleno verano para nosotros. ¡Pero mucho peor que las de la presidencia con el Congreso! Aunque no tan perjudicial (1909: 36).

En política o en mecánica social, ocultarse podrá ser sinónimo de eclipsarse; pero en astronomía no (1917: 293).

Muchos de sus textos se articularon como respuestas a preguntas que el público lector, de manera oral o escrita, le planteaba. Lamentablemente no contamos hoy con esos originales posiblemente llegados a la redacción del diario, a su domicilio o transmitidos oralmente. Sí pueden extraerse algunos de los propios textos de Gil y son dignos de transcribirse:

La dirección de una revista de agricultura del litoral, se dignaba a preguntarme no ha mucho, si realmente la Luna llena tendría influencia sobre la poda de las plantas y la germinación, etc., es decir, si no habría algo de verdad en esos prejuicios de los agricultores (1917: 90).

Unos estudiantes de cosmografía formulan estas dos preguntas: ¿Cuál es la menor distancia posible de la Luna a la Tierra y cuál fue la posición y el estado de la Luna en la noche de la declaratoria de nuestra independencia el 9 de julio de 1816, y cuál será ahora, para la fiesta del centenario? (1917: 91).

Bien pues; sobre un mismo tema he recibido varias preguntas de carácter alarmante diciendo: "Señor, ¿es verdad que de hoy en adelante el mes de febrero no volverá a tener en ningún momento veintinueve (29) días como le ha sucedido siempre cada cuatro años, hasta dentro de tres siglos?" (1917: 169).

Como decíamos, la imaginación popular gira alrededor del agua de lluvia, revoloteando en general por las alturas. Dentro del número de preguntas y consideraciones de orden científico que se me formulan a diario, ha comenzado a predominar la siguiente: si las grandes lluvias y continuo mal tiempo en Europa desde el año pasado hasta hoy podría atribuirse a la guerra, al continuo bombardeo, como afirma mucha gente (1917: 155).

Los comienzos de los textos imponen una manera de leer, diseñan discursivamente a su lector, suponen actitudes de quien habla y escucha, anticipan intereses, tonalidades de la voz y frecuentemente suscitan el deseo de continuar leyendo. Estos interrogantes, que debieron ser genuinos, resultan entrañables al revelar inquietudes dispares - a veces comunes, a veces ingenuas - surgidas de simples curiosidades que seguramente albergaba la imaginación de la gente. A partir de esos comienzos, la respuesta implicaba un extenso desarrollo en el que la modulación conversacional animaba la prosa. Martín Gil convocaba a su lector y parecía estar atento a sus interrogantes: fórmula de comunicación que proveía a la escritura, de

13 Se refiere a la estrella Sirio de la constelación del Gran Can. 
por sí descontextualizada, de la coloración propia de las interacciones orales y más aun de una cierta cordialidad que aceptaba y respetaba las dudas, que reconocía al lector y rechazaba la "seriedad doctoral" que animaba el discurso de la comunidad científica de la época. En todo caso si no había consultas, él mismo luego de algunas afirmaciones se anticipaba a los interrogantes del lector: "Pero alguien me preguntará...”

A falta de una interpelación, solía comenzar comentando noticias de la prensa relativas a la astronomía, las que servían como disparador para encarar la explicación de algún fenómeno: "Tengo aquí en mi mesa de trabajo unos cuantos artículos que me han llamado la atención. Esos artículos se titulan 'El día se alarga', 'Los habitantes de Júpiter' y 'El cometa Halley'” (1909: 153). Esto demuestra, por un lado, el interés de la prensa en general por los fenómenos celestes, y, por otro, también una estrategia que le permitía a Gil excitar la atención para completar, esclarecer u oponerse a los artículos citados.

En muchas oportunidades fue intuitivo en los temas de interés y no desperdició lo que él llamaba "el diapasón del momento", esto es, aquellas temáticas que podían interesar al público porque se encontraban próximas de alguna manera a su experiencia cotidiana: los viajes al polo, la inutilidad del cambio de hora que había sido propuesto en 1911 o simplemente, según la época del año, destinaba los artículos a la visión que del cielo en ese mes se podía tener desde algunas regiones de la Argentina. Se denominaban Nuestro cielo de abril, Nuestro cielo de septiembre, etc. $y$ fueron reconocidos como un gran acierto por Ángel Gallardo ${ }^{14}$ en cuanto las descripciones con las que se contaba en aquel momento en el país sometían al lector a un molesto rompecabezas para "adaptar á lo que vemos una descripción hecha en otro hemisferio" (1909: iii).

Si por un lado el desarrollo de los temas se hacía en un marco conversacional, cada cuestión en particular se contextualizaba con breves referencias históricas o bien, a la manera de una progresión didáctica, partía de los elementos más básicos para estimular su comprensión: si se trataba de hablar sobre los viajes al polo, planteaba para qué o qué utilidad tenían esas expediciones; si se requería juzgar las propuestas de cambio de hora, la explicación emergía en el cuadro de una reflexión general sobre el concepto de tiempo; si se necesitaba comentar sobre el cometa Halley explicaba qué eran los cometas y se nutría de múltiples ejemplos para hacerlo.

14 Ingeniero civil y doctor en ciencias naturales. 
Aun cuando la precisión no estuvo ausente de sus escritos, la conquista del lector debía humanizar un mundo distante; por eso, en lugar de traducir un lenguaje complejo a otro simple, optó por mostrar el mundo celeste concebido en aquel momento como majestuoso y solemne y transformarlo en espectáculo. Atendiendo a las visiones de su época e inscribiéndose en una antigua tradición de divulgación de la astronomía, convirtió el cielo en una escena habitada en la que armonizaba la explicación precisa con la selección de figuras, especialmente la prosopopeya y la metáfora de las que hizo un uso recurrente. La astronomía es una ciencia con un significativo componente poético que suscita, según cada tiempo, fuertes imaginarios sociales (Beacco, 2000). Las dos figuras contribuyen a narrativizar la explicación de los fenómenos nutriendo fantasías que se anclaban en el misterio del mundo celeste. Planetas y cometas, mutando en personajes, recorren solemnemente el espacio caminado o navegando. Así decía de Halley que:

...viene caminando hacia nosotros desde las profundidades del cielo ...y arribará a nuestras costas con su gran vela desplegada al éter en 1910, justamente en la época de nuestra gran fiesta del centenario, siendo quizás quien anuncie el alba clásica del 25 de mayo ó el que brille dulcemente en el crepúsculo vespertino de ese día glorioso (1909: 135).

...en estos momentos debe navegar, según cálculo, entre las aguas de Saturno y Júpiter... Arribará a nuestras costas con su gran vela desplegada al éter en 1910. (1909: 3).

y de Marte:

El otro heraldo es nada menos que el dios de la guerra en persona. Marte, el sanguinario, el más odioso de los inmortales al decir de los poetas paganos. Casi invisible en estos momentos por encontrarse angularmente muy cerca del Sol, hace sus correrías sobre la constelación de la Virgen, profanando con su roja presencia esa mística región del cielo (1909: 4).

Construía de esta manera una suerte de escena celeste cuyos habitantes se trasladaban en una dinámica majestuosa. Por eso, nunca despojó al cielo de sus posibles e impenetrables enigmas, posiblemente para conservar la atractiva belleza de lo arcano $^{15}$ :

Y todo lo que llega desde lo alto, de lo desconocido, inclusive lo malo y fatal, tiene, en el fondo su poesía amable o siniestra: la poesía del misterio (1935: 33).

En las antípodas de la aridez del discurso científico-académico, el suyo se define por las vías de múltiples recursos literarios de gran poder seductor para el público de su época. Quien lo leía seguramente podía sentir que "escuchaba" una

15 Véase Cazaux (2010: capítulo 4). 
narrativa agradable en donde discurría la explicación racional de los fenómenos celestes atravesada simultáneamente por metáforas que nunca despojaron al cielo de sus perpetuos secretos.

\section{Conclusión}

La imagen y los discursos de Martín Gil resultan interesantes si no en el campo de la astronomía, sí en el de la divulgación por cuanto concentra cuestiones significativas. En primer lugar, las determinaciones exteriores al discurso constituidas por factores académicos y socio-políticos que, como en el caso de Gil, constituyeron un campo conflictivo. Sus textos dan cuenta de una fuerte tensión en la época en lo que respecta a los desarrollos de la astronomía en la Argentina y, de la misma manera, esa tensión determina que él saturara un vacío. Pero también es necesario tener en cuenta como condicionamiento significativo no solo el tipo de saber que difundía sino también el soporte que lo alojón ${ }^{16}$; función que Martín Gil cumplió con clara conciencia en lo referido a sus relaciones con un público amplio. Algunas de sus estrategias se vigorizan en la prensa porque van dirigidas a numerosos lectores. $\mathrm{Y}$ ya se conoce que en este caso el soporte es determinante en relación con las estrategias discursivas: los lectores buscan los libros, pero los periódicos van en busca de sus lectores.

Más allá de las condiciones de producción que determinaron la labor de Martín Gil en la que, como ya se vio, se observan componentes político-partidarios importantes y aun su condición de divulgador en el marco de una teoría astronómica de poca aceptación en el mundo científico, se torna en una figura legitimada en su época para la tarea; es decir que supo divulgar "en forma amena y agradable [...] la sólida y exacta información astronómica" (Gallardo, 1909: i). Sus discursos divulgativos se publicaron de manera sistemática y - si bien se reiteraba en el diario $\mathrm{La}$ Nación este tipo de artículos firmados, la mayoría de las veces por autores extranjeros con un texto al menos tedioso- es el único que se erigió como divulgador conocido y celebrado por el público.

Sería posible arriesgar que encarnó la figura social del divulgador en la prensa argentina de su época siguiendo con la afirmación de Gerchunoff según la cual había logrado popularizar lo que hasta ese momento en la Argentina "preocupaba a grupos limitados" con referencia especialmente en la astronomía. Alcanzó cierta

16 Véase al respecto Beacco, 2000. 
familiaridad con el lector, era citado por otros diarios, era consultado asiduamente; en fin, representaba ese gesto de proximidad que quien no es especializado requiere para acercarse a un saber. El éxito de la labor de Martín Gil se encontraba en el estilo, en su modo de hacer, en el modo de referir los fenómenos astronómicos, lo que puede considerarse una clave para cualquier discurso de divulgación si se la piensa como la explicación de la ciencia a un público numeroso y no especializado.

La misma resistencia que emergía en torno de la labor divulgativa de Martín Gil posiblemente atraviesa todavía hoy el campo con las variantes que impone otro momento socio-histórico. Esto es, pareciera que no se concluye de resolver una cuestión central. Nos referimos a la relación entre científicos y divulgadores en la prensa. A diferencia de la intransigencia hallada en los comienzos del siglo $\mathrm{XX}$, hoy la divulgación ha sido reconocida y valorada en el mundo científico; no obstante se discute sobre quién debe hacerla, sobre cómo hacerla, sobre los conocimientos y las destrezas que deben nutrir a sus agentes, sobre las diferentes lógicas de trabajo de científicos y periodistas, sobre las posibles desviaciones del saber académico en los medios en general.

Hoy no sería posible recurrir a la misma retórica pero subsiste como ilustración una alianza que parece estar todavía vigente. Martín Gil encontró las estrategias que en su época resultaron apropiadas, pero que ahora podrían repensarse en los mismos términos: el de las relaciones entre periodismo y literatura.

\section{Referencias}

Beacco, Jean Claude (2000). "Écritures de la science dans les médias". Les Carnets du Cesdiscor, 6: 1524. Consultado el 15 de septiembre de 2012 en: http://cediscor.revues.org/319

Cazaux, Diana (2010). Historia de la divulgación científica en la argentina. Buenos Aires: Teseo.

Charaudeau, Patrick (1995, juin): "Ce que communiquer veut dire". Revue des Sciences Humaines, 51. Consultado el 15 de septiembre de 2012 en: http://www.patrick-charaudeau.com/Ce-quecommuniquer-veut-dire.html

Echagüe, Pedro (1938). Seis figuras del Plata. Buenos Aires: Losada.

Gallardo, Ángel (1909). “Del ingeniero y doctor en ciencias, Prof. Ángel Gallardo”. En: Gil, Martín. Cosas de arriba. Córdoba: Establecimiento tipográfico "La Italia".

Genette, Gerard (1989). Figuras III. Barcelona: Lumen.

Gerchunoff, Alberto (1935). “Martín Gil”. En: Gil, Martín. Hablando solo. Buenos Aires: Talleres Gráficos Porter Hnos.

Gil, Martín (1900). Prosa rural. Córdoba: [s.n.].

- (1903). Modos de ver. Córdoba: Establecimiento tipográfico "La Italia". (1909). Cosas de arriba. Córdoba: Establecimiento tipográfico "La Italia". 
- (1917). Celestes y cósmicas. Córdoba: Imprenta Cubas.

(1924 [1906]). Agua mansa. Buenos Aires: Babel.

(1930). Un anillo desaparecido. Buenos Aires: M. Gleizer.

(1930). Mirar desde arriba. Buenos Aires: M. Gleizer.

(1935). Hablando solo. Buenos Aires: Talleres Gráficos Porter Hnos.

(1936). Misterios, planetas y petróleos. 4a. ed. Buenos Aires: Compañía General Fabril Financiera.

(1960). Antología. Buenos Aires: Academia Argentina de Letras.

Hurtado, Diego (2010). La ciencia argentina: un proyecto inconcluso, 1930-2000. Buenos Aires: Edhasa.

Paolantonio, Santiago \& Minniti, Edgardo (2009). "Historia del Observatorio Astronómico de Córdoba" (p. 51-167). En: Workshop de historia de la astronomía argentina (2008, La Plata). Historia de la astronomía argentina. La Plata: Asociación Argentina de Astronomía. (Asociación Argentina de Astronomía book series; 2). Consultado el 10 de septiembre de 2012 en: http:// historiadelaastronomia.files.wordpress.com/2008/12/historia-del-ona1.pdf

Sarlo, Beatriz (1992). La imaginación técnica: sueños modernos de la cultura argentina. Buenos Aires: Nueva Visión.

\section{Correspondencia}

\section{Paulina Maritza Brunetti}

Escuela de Ciencias de la Información de la Universidad Nacional de Córdoba

brunettipaulina@gmail.com 